\title{
MODELLING THE UNDRAINED RESPONSE OF FIBRE REINFORCED SANDS
}

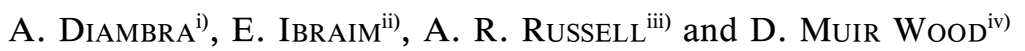

\begin{abstract}
Mixing a loose clean sand with random discrete flexible fibres has been found beneficial in decreasing the susceptibility to the phenomenon of liquefaction under monotonic loading. The addition of fibres can convert the strain softening response, typical of a loose unreinforced sand, into a strain hardening response by affecting the pore pressure generation and the effective stress path response. A new constitutive model based on the rule of mixtures has been used to simulate the undrained response of fibre reinforced sands. The model superimposes the individual contributions of the sand and the fibres according to their volumetric fraction. An apparent densification of the sand matrix induced by the presence of the fibres is accounted for in the model by assigning some of the void space to the fibres. This apparent densification is considered responsible for the observed strain hardening behaviour of reinforced sands. The proposed model is able to accommodate any distribution of fibre orientation: the orientation of fibres plays a key role in explaining the experimentally observed effective stress paths.
\end{abstract}

Key words: constitutive modelling, fibre orientation, liquefaction, sand, soil with inclusions, undrained behaviour (IGC: A10/D6/D10)

\section{INTRODUCTION}

Reinforcement of soils by mixing with discrete flexible fibres is a relatively new technology with unique benefits that have not yet been widely exploited in industry. The fibre reinforcement is known to increase the strength of the soils and, if used carefully, the mixed soil can reduce lateral earth pressures acting on retaining structures, aid the repair of unstable slopes, and increase the ultimate bearing capacities of shallow foundations. However, a recent experimental investigation (Ibraim et al., 2010) the first published attempt to study the effect of fibre inclusions on the undrained response of sand under monotonic loading-has also demonstrated the benefit of fibre reinforcement for reducing the liquefaction potential of loose clean sands under monotonic loading. These experimental findings are considered of particular significance for the future applicability of fibre reinforcement to the prevention of failures caused by static liquefaction of soils. However, they also revealed some surprising aspects of the behaviour of the composite material.

None of the constitutive models published so far has yet succeeded to reproduce the undrained behaviour of fibre reinforced sands. Most of the proposed modelling approaches have concentrated on the prediction of the contribution of the fibres to the increase in shear strength
(Waldron, 1977; Gray and Ohashi, 1983; Gray and AlRefeai, 1986; Michałowski, 1997; Michałowski and Čermák, 2002; Zornberg, 2002) and only a few authors have tried to propose a general constitutive law for reinforced soils (Villard et al., 1990; di Prisco and Nova, 1993; Ding and Hargrove, 2006; Li and Ding, 2002). However, the fibre orientation has often not been considered when modelling the behaviour of reinforced soils whereas the importance of the actual orientation of fibres in the analysis of real geotechnical systems has been demonstrated by Michałowski (2008).

A complete constitutive model for reinforced soils which can take account of any distribution of fibre orientation has been proposed by Diambra et al. (2010). This model has been further extended here to simulate the undrained features of the behaviour of fibre reinforced sands. As suggested in Diambra (2010), a more advanced model for the sand matrix has been considered and the apparent densification effect induced by the presence of the fibres has been accounted for, based on the experimental data by Ibraim et al. (2010).

\section{NOTATION}

The notation for the stress and strain variables adopted in this study mainly uses the conventional definitions for axisymmetric triaxial conditions. Thus, $p$ and $q$ are re-

i) Lecturer, Department of Civil Engineering, University of Bristol, United Kingdom (andrea.diambra@bristol.ac.uk).

ii) Reader, ditto.

iii) Senior Lecturer, School of Civil and Environmental Engineering, The University of New South Wales, Australia.

iv) Professor, Department of Civil Engineering, University of Dundee, United Kingdom.

The manuscript for this paper was received for review on June 18, 2010; approved on February $10,2011$.

Written discussions on this paper should be submitted before May 1, 2012 to the Japanese Geotechnical Society, 4-38-2, Sengoku, Bunkyo-ku,

Tokyo 112-0011, Japan. Upon request the closing date may be extended one month. 
spectively the total mean stress and deviatoric stress acting on the composite, and $p^{*}$ is the effective mean stress defined as $p^{*}=p-u$ where $u$ is the pore water pressure. Although the deviator stress is unaffected by pore water pressure, for uniformity of notation, the deviator stress on the composite will be denoted as $q^{*}$. The strain variables of the composite are the volumetric strain, $\varepsilon_{v}$, and shear strain, $\varepsilon_{\mathrm{q}}$. These stress and strain quantities are related to axial and radial stresses and strains according to:

$$
\begin{array}{ll}
p=\frac{\sigma_{\mathrm{a}}+2 \sigma_{\mathrm{r}}}{3} & q=\sigma_{\mathrm{a}}-\sigma_{\mathrm{r}} \\
\varepsilon_{v}=\varepsilon_{\mathrm{a}}+2 \varepsilon_{\mathrm{r}} & \varepsilon_{\mathrm{q}}=\frac{2}{3}\left(\varepsilon_{\mathrm{a}}-\varepsilon_{\mathrm{r}}\right)
\end{array}
$$

where subscripts ' $a$ ' and ' $r$ ' denote the axial and radial components respectively.

The stress and strain variables can also be related to the two phases, sand matrix and fibres. In this case the effective stress state of the sand matrix is denoted by the dash $\left(\sigma^{\prime}=\left[p^{\prime}, q^{\prime}\right]^{\mathrm{T}}\right)$ and the strain state with the subscript ' $\mathrm{m}$ ' $\left(\varepsilon_{\mathrm{m}}=\left[\varepsilon_{\mathrm{m} v}, \varepsilon_{\mathrm{mq}}\right]^{\mathrm{T}}\right)$. The stress and strain states of the fibres phase are denoted with the subscript ' $\mathrm{f}$ ', $\left(\sigma_{\mathrm{f}}=\left[p_{\mathrm{f}}, q_{\mathrm{f}}\right]^{\mathrm{T}}\right)$ and $\left.\left(\varepsilon_{\mathrm{f}}=\varepsilon_{\mathrm{f} v}, \varepsilon_{\mathrm{fq}}\right]^{\mathrm{T}}\right)$ respectively. Bold symbols indicate vector or matrix quantities.

\section{MODELLING FRAMEWORK}

\section{Rule of Mixtures}

The modelling framework proposed by Diambra et al. (2010) is summarised and amended here. The constitutive model is developed using the rule of mixtures for composite materials which is based on the following assumptions:

- each component of a composite satisfies its own constitutive law,

- each component is homogeneously distributed throughout the composite,

- the contribution of each component to the overall composite behaviour is scaled according to its individual volumetric fraction.
The total volume of an unreinforced specimen $(V)$ is made up of a sand matrix $\left(V_{\mathrm{s}}\right)$ and voids $\left(V_{\mathrm{v}}\right)$ and its phase diagram is schematically shown in Fig. 1(a). A similar phase diagram can be proposed for a fibre reinforced soil, Fig. 1(b), where $V_{\mathrm{f}}$ is the volume of fibres. However, based on recent experimental findings by Diambra (2010) and Ibraim et al. (2010), it is suggested that the volume of voids should be divided into two parts 'attached' respectively to the sand matrix $\left(V_{\mathrm{vs}}\right)$ and to the fibres $\left(V_{\mathrm{vf}}\right)$, Fig. 1(c). In these experimental studies, the volumetric response of the composite has seemed to imply an apparent densification mechanism of the sand matrix resulting from the presence of the fibres in the voids. Although the global void ratio of the composite was not changed significantly by the volume of the inclusions themselves, the fibres had 'stolen' additional voids-hence the additional matrix densification.

The specific volumes for a fibre reinforced specimen $(v)$, sand matrix $\left(v_{\mathrm{m}}\right)$ and fibres $\left(v_{\mathrm{f}}\right)$ can be defined as follows:

$$
v=\frac{V}{V_{\mathrm{s}}+V_{\mathrm{f}}} \quad v_{\mathrm{m}}=\frac{V_{\mathrm{vs}}+V_{\mathrm{s}}}{V_{\mathrm{s}}} \quad v_{\mathrm{f}}=\frac{V_{\mathrm{vf}}+V_{\mathrm{f}}}{V_{\mathrm{f}}}
$$

and they are linked by the relationship:

$$
v=\left(v_{\mathrm{m}}+v_{\mathrm{f}} \frac{G_{\mathrm{s}} w_{\mathrm{f}}}{G_{\mathrm{f}}}\right) \frac{G_{\mathrm{f}}}{G_{\mathrm{f}}+G_{\mathrm{s}} w_{\mathrm{f}}}
$$

where $G_{\mathrm{s}}$ and $G_{\mathrm{f}}$ are the specific gravities of the sand grains and fibres respectively, and $w_{\mathrm{f}}$ is the average concentration of fibres included in a composite defined as a proportion of dry weight of sand:

$$
w_{\mathrm{f}}=\frac{W_{\mathrm{f}}}{W_{\mathrm{s}}}
$$

where $W_{\mathrm{f}}$ is the weight of fibres and $W_{\mathrm{s}}$ is the dry weight of sand.

The relationship between the incremental specific volume of the composite and its volumetric strain is:

$$
\dot{\varepsilon}_{v}=-\frac{\dot{v}}{v}
$$

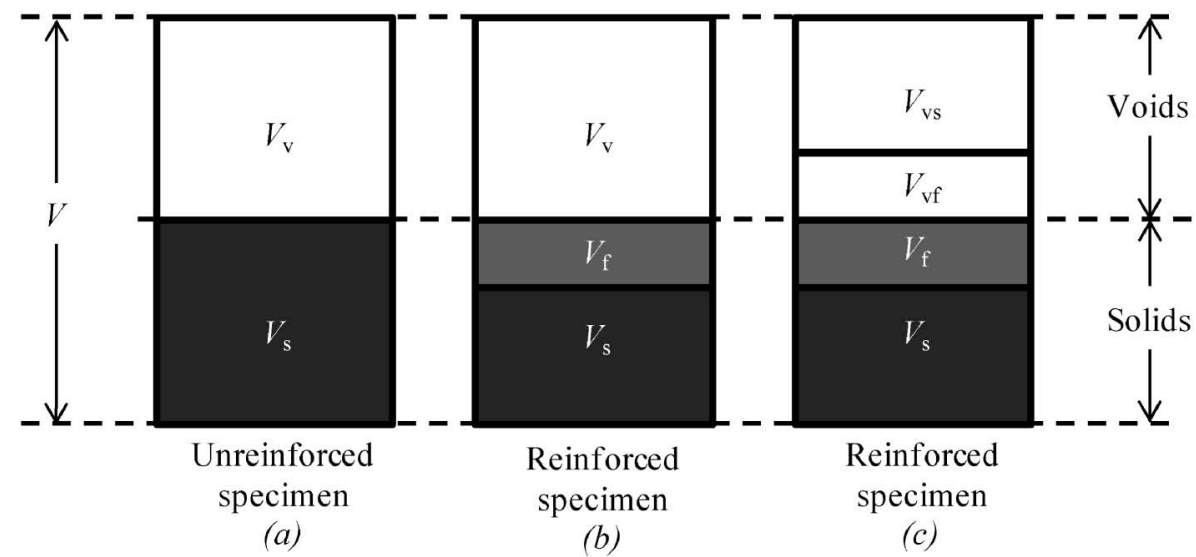

Fig. 1. Phase diagram for (a) unreinforced specimen, (b) reinforced specimen without partition of volume of voids and (c) reinforced specimen with partition of volume of voids 
and this can be applied equally to the sand and fibre phases of the composite material:

$$
\dot{\varepsilon}_{\mathrm{m} v}=-\frac{\dot{v}_{\mathrm{m}}}{v_{\mathrm{m}}} \quad \dot{\varepsilon}_{\mathrm{f} v}=-\frac{\dot{v}_{\mathrm{f}}}{v_{\mathrm{f}}}
$$

By manipulating Eqs. (4), (6) and (7), the relationship between the incremental volumetric strains of the composite $\left(\dot{\varepsilon}_{v}\right)$ and its constituents $\left(\dot{\varepsilon}_{\mathrm{m} v}, \dot{\varepsilon}_{\mathrm{fv}}\right)$ can be determined:

$$
\dot{\varepsilon}_{v}=\dot{\varepsilon}_{\mathrm{m} \nu} \mu_{\mathrm{m}}+\dot{\varepsilon}_{\mathrm{fv}} \mu_{\mathrm{f}}
$$

where

$$
\mu_{\mathrm{m}}=\frac{\left(V_{\mathrm{s}}+V_{\mathrm{vs}}\right)}{V} \text { and } \mu_{\mathrm{f}}=\frac{\left(V_{\mathrm{f}}+V_{\mathrm{vf}}\right)}{V}
$$

are the volume fractions of sand and fibres with their specific 'attached' voids.

Maintaining consistency with Eq. (8) and the rule of mixtures, it is assumed that the distortional strains of the phases can be directly summed to determine the distortional strain of the composite material. It follows that the relationship between the incremental vector of strains of the composite and its constituents can be defined as:

$$
\dot{\varepsilon}=\dot{\boldsymbol{\varepsilon}}_{\mathrm{m}} \mu_{\mathrm{m}}+\dot{\boldsymbol{\varepsilon}}_{\mathrm{f}} \mu_{\mathrm{f}}
$$

and no compatibility between the incremental strains of the fibres and sand is imposed at this stage.

$$
\left[\begin{array}{c}
\dot{\sigma}_{\mathrm{af}} \\
\dot{\sigma}_{\mathrm{rf}}
\end{array}\right]=\left[\begin{array}{l}
\frac{E_{\mathrm{f}}}{\mu_{\mathrm{f}}} \int_{1_{1}}^{l_{2}} \rho(\theta) \cos (\theta) \sin ^{4}(\theta) \mathrm{d} \theta \\
\frac{E_{\mathrm{f}}}{\mu_{\mathrm{f}}} \frac{1}{2} \int_{1_{1}}^{l_{2}} \rho(\theta) \cos ^{3}(\theta) \sin ^{2}(\theta) \mathrm{d} \theta
\end{array}\right.
$$

This particular formulation considers each fibre behaving as a linear elastic material described by the Young's modulus of the fibres $\left(E_{\mathrm{f}}\right)$, taking into account any particular distribution of fibre orientation $(\rho(\theta))$ and allowing for imperfect bonding (or partial sliding) between the fibres and the sand matrix through a dimensionless fibre sliding function, $f_{\mathrm{b}},\left(f_{\mathrm{b}}=1\right.$ for perfect bonding between fibres and sand grains and $f_{\mathrm{b}}=0$ for full sliding).

The fibre orientation distribution function, $\rho(\theta)$, is defined in spherical coordinates and represents the volumetric concentration of fibres in an infinitesimal volume $\mathrm{d} V$ (Fig. 2) having an orientation $\theta$ to the horizontal (Michałowski and Čermák, 2002; Diambra et al., 2007). The normalised integral of the fibre orientation distribution function over the generic reference spherical volume $V_{\text {ref }}$ gives the average fibre concentration $\bar{\rho}$ :

$$
\bar{\rho}=\frac{1}{V_{\text {ref }}} \int_{\mathrm{V}_{\text {ref }}} \rho(\theta) d V
$$

The average fibre concentration, $\bar{\rho}$, is also defined by:

$$
\bar{\rho}=V_{\mathrm{f}} / V
$$

where $V$ is the total volume of the composite.
The application of the rule of mixtures for the composite stresses can be derived from the equilibrium of forces acting on the composite material and on its constituents. It is assumed here that the constituent phases are homogeneously distributed throughout the sample and the area ratio of fibres in any cross-section is the same as the volume ratio. Therefore, the stress state of the composite, $\sigma^{*}$, can be expressed in terms of the stress states of the soil matrix $\sigma^{\prime}=\left[p^{\prime}, q^{\prime}\right]^{\mathrm{T}}$ and fibres $\sigma_{\mathrm{f}}=\left[p_{\mathrm{f}}, q_{\mathrm{f}}\right]^{\mathrm{T}}$ according to:

$$
\sigma^{*}=\sigma^{\prime} \mu_{\mathrm{m}}+\sigma_{\mathrm{f}} \mu_{\mathrm{f}}
$$

and its incremental form is:

$$
\dot{\sigma}^{*}=\mu_{\mathrm{m}} \dot{\sigma}^{\prime}+\dot{\mu}_{\mathrm{m}} \sigma^{\prime}+\mu_{\mathrm{f}} \dot{\sigma}_{\mathrm{f}}+\dot{\mu}_{\mathrm{f}} \sigma_{\mathrm{f}}
$$

The constitutive relationship for the composite results is obtained by solving simultaneously Eqs. (10) and (12) and it will be completely defined from the constitutive relationships of the individual constituents.

\section{Constitutive Model for Fibres}

For fibre orientation distributions which are symmetrical with respect to the vertical axis, Diambra et al. (2010) proposed the following incremental stress-strain relationship for fibres (the full derivation is detailed in the APPENDIX):

$$
\left.\begin{array}{l}
\frac{E_{\mathrm{f}}}{\mu_{\mathrm{f}}} \int_{\mathrm{l}_{1}}^{\mathrm{l}_{2}} \rho(\theta) \cos ^{3}(\theta) \sin ^{2}(\theta) \mathrm{d} \theta \\
\frac{E_{\mathrm{f}}}{\mu_{\mathrm{f}}} \frac{1}{2} \int_{1_{1}}^{l_{2}} \rho(\theta) \cos ^{5}(\theta) \mathrm{d} \theta
\end{array}\right] f_{\mathrm{b}}\left[\begin{array}{c}
\dot{\varepsilon}_{\mathrm{a}} \\
\dot{\varepsilon}_{\mathrm{r}}
\end{array}\right]
$$

It is assumed that the fibres have no resistance to either compression or bending: they only contribute to the stiffness and strength of the composite when they are in tension. For this reason the integrals in Eq. (13) have the limits $l_{1}=0$ and $l_{2}=\theta_{0}$ for triaxial compression and $l_{1}=\theta_{0}$ and $l_{2}=\pi / 2$ for triaxial extension (Fig. 3). $\theta_{0}$ is the direction of zero incremental strains which, according to Mohr's circle for strain increment, is:

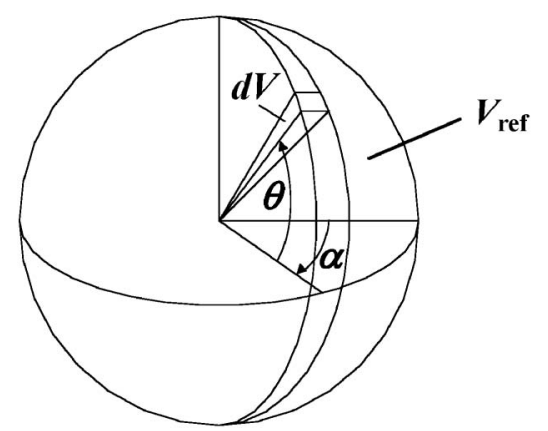

Fig. 2. Spherical coordinates used for the definition of the fibre orientation distribution 


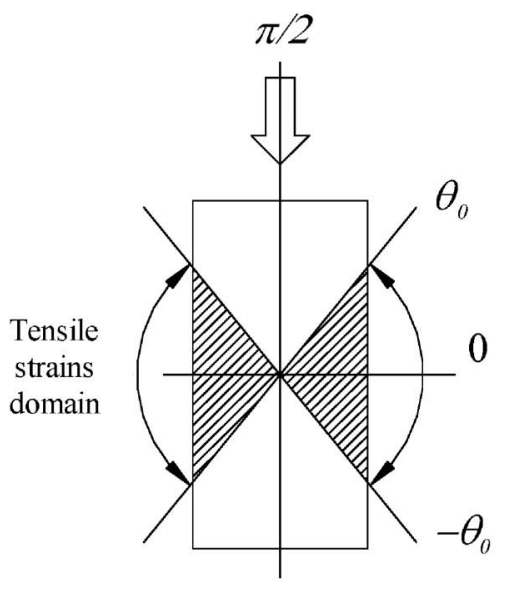

(a)

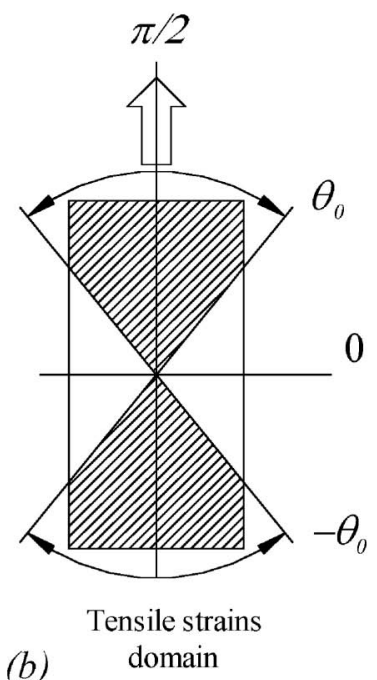

(b)

Fig. 3. Domains of tensile strain orientations for (a) compression and (b) extension loading

$$
\theta_{0}=\arctan \sqrt{-\frac{\dot{\varepsilon}_{\mathrm{r}}}{\dot{\varepsilon}_{\mathrm{a}}}}
$$

Using conventional triaxial $p_{\mathrm{f}}-q_{\mathrm{f}}$ notation, and when the distribution of fibre orientations is symmetrical with respect to the vertical axis, Eq. (13) becomes:

$$
\left[\begin{array}{c}
\dot{p}_{\mathrm{f}} \\
\dot{q}_{\mathrm{f}}
\end{array}\right]=\left[\begin{array}{ll}
M_{11} & M_{12} \\
M_{21} & M_{22}
\end{array}\right] f_{\mathrm{b}}\left[\begin{array}{c}
\dot{\varepsilon}_{v} \\
\dot{\varepsilon}_{\mathrm{q}}
\end{array}\right]
$$

where:

$$
\left.\begin{array}{l}
M_{11}=\frac{1}{9}\left(F_{11}+F_{12}+2 F_{21}+2 F_{22}\right) \\
M_{12}=\frac{1}{3}\left(F_{11}-\frac{F_{12}}{2}+2 F_{21}-F_{22}\right) \\
M_{21}=\frac{1}{3}\left(F_{11}+F_{12}-F_{21}-F_{22}\right) \\
M_{22}=\frac{1}{2}\left(2 F_{11}-F_{12}-2 F_{21}+2 F_{22}\right)
\end{array}\right\}
$$

and the $F_{\mathrm{ij}}$ terms represent the components of the matrix in Eq. (13) with the first subscript being the column number and the second subscript being the row number.

\section{Constitutive Model for Sand Matrix}

The present modelling framework based on the rule of mixtures provides complete freedom in selecting the constitutive relationships for its constituents. The SevernTrent sand model (Gajo and Muir Wood, 1999) successfully simulates the behaviour of sands and it has already been applied to Hostun RF sand (employed in this experimental investigation of fibre reinforced sand). Therefore this model is used here for the sand matrix.

Severn-Trent sand is a bounding surface, kinematic hardening soil model. The strength surface represents the bounding surface and always encloses the yield surface (Fig. 4). Both the strength and yield surfaces are wedges in the $q^{\prime}-p^{\prime}$ plane with their apexes coincident with the origin of the plane. The size of the strength surface de-

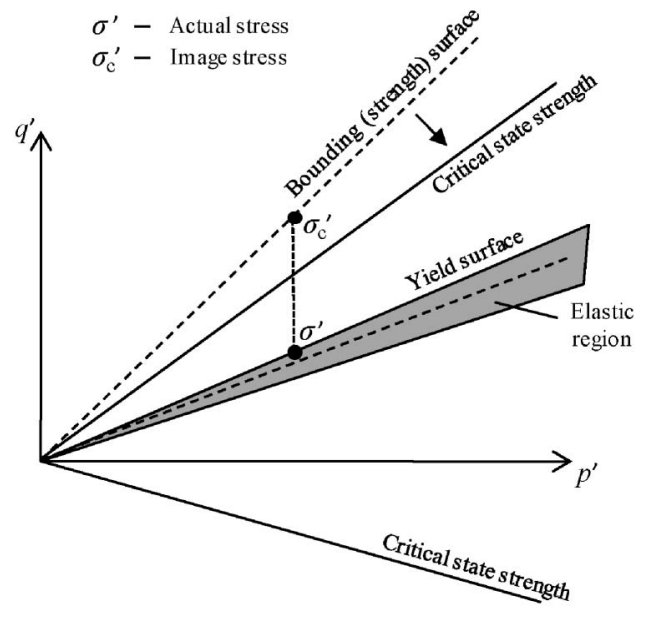

Fig. 4. Schematic view of the strength surface and elastic region for the Severn-Trent model (Gajo and Muir Wood, 1999)

pends on the current value of state parameter $\xi$ (Been and Jefferies, 1985) which describes the volumetric distance from the locus of ultimate critical states. The model is formulated in a "normalised" stress space $\left(\bar{\sigma}^{\prime}=\left[\bar{p}^{\prime}\right.\right.$, $\left.\bar{q}^{\prime}\right]^{\mathrm{T}}$ ) where the deviatoric stress is divided by $r=1-k_{\mathrm{r}} \xi$ with $k_{\mathrm{r}}$ being a constitutive parameter:

$$
\bar{q}^{\prime}=\frac{q^{\prime}}{r} \quad \text { and } \quad \bar{p}^{\prime}=p^{\prime}
$$

In the "normalised" stress space, the size of the strength surface $F(\bar{\sigma})$ remains constant and it is defined as:

$$
F(\bar{\sigma})=t\left(\bar{q}^{\prime}-M p^{\prime}\right)
$$

where $M$ is the stress ratio at critical state and $t=+1$ or $t$ $=-1$ distinguishes between a compression or extension approach to failure, respectively.

The yield surface $f(\bar{\sigma})$ bounds a purely elastic region and it is expressed by:

$$
f(\bar{\sigma})=\bar{q}^{\prime}\left(\alpha_{\mathrm{p}}-t n_{\mathrm{y}} \alpha_{\mathrm{q}}\right)-p^{\prime}\left(\alpha_{\mathrm{q}}-t n_{\mathrm{y}} \alpha_{\mathrm{p}}\right)
$$


where $\alpha_{\mathrm{p}}$ and $\alpha_{\mathrm{q}}$ are the components of the vector $\alpha$ which defines the direction of the central axis of the surface. The parameter $n_{\mathrm{y}}$ is the stress ratio defined from the friction angle $\phi_{\mathrm{y}}^{\prime}$ of the yield surface which is in turn related to the critical state friction angle $\phi^{\prime}$ by the relationship:

$$
\sin \phi_{\mathrm{y}}^{\prime}=R \sin \phi^{\prime}
$$

where $R$ is a constitutive parameter which links the size of the yield surface to the size of the strength surface at critical state conditions. The components of the unit normal vector $\boldsymbol{n}=\left[n_{\mathrm{p}}, n_{\mathrm{q}}\right]^{\mathrm{T}}$ to the yield surface are:

$$
n_{\mathrm{p}}=\frac{-\bar{\eta}}{\sqrt{1+\bar{\eta}^{2}}} \quad n_{\mathrm{q}}=\frac{1}{\sqrt{1+\bar{\eta}^{2}}} \quad \text { with } \quad \bar{\eta}=\frac{\bar{q}^{\prime}}{p^{\prime}}
$$

The model assumes a non associative flow rule which is a modification of the original Cam-Clay flow rule (Roscoe and Schofield, 1963). The ratio between the plastic volumetric and deviatoric strain increments is:

$$
d=\frac{\dot{\varepsilon}_{\mathrm{m} v}}{\dot{\varepsilon}_{\mathrm{mq}}}=A\left[M\left(1+k_{\mathrm{d}} \xi\right)-\eta\right]
$$

where $A$ and $k_{\mathrm{d}}$ are two constitutive parameters. The flow rule ensures that shearing at stress ratios below or above the critical state stress ratio produces plastic volumetric compression (densification) or expansion (dilation) so that shearing automatically steers the sand towards the critical state-though this ultimate strength can only be reached after infinite shear strain. The components of the unit normal vector of the plastic flow $\boldsymbol{m}=\left[m_{\mathrm{p}}, m_{\mathrm{q}}\right]^{\mathrm{T}}$ are:

$$
m_{\mathrm{p}}=\frac{d}{\sqrt{1+d^{2}}} \quad m_{\mathrm{q}}=\frac{1}{\sqrt{1+d^{2}}}
$$

The hardening parameter $H$, which controls the magnitude of the plastic strains, is:

$$
H=\frac{b^{2}}{B b_{\max }}
$$

where $B$ is a constitutive parameter, $b$ depends on the distance between the actual stress state $\left(\bar{q}^{\prime}\right)$ and its image on the bounding $\left(\bar{q}_{\mathrm{c}}^{\prime}\right)$ surface defined in the normalised space:

$$
b=n_{\mathrm{q}}\left(\bar{q}_{\mathrm{c}}^{\prime}-\bar{q}^{\prime}\right)
$$

and $b_{\max }$ is the maximum possible value of $b$ in the normalised stress space.

In the normalised stress space the constitutive relationship takes the following form:

$$
\dot{\overline{\boldsymbol{\sigma}}}^{\prime}=\left[\overline{\bar{D}}^{\mathrm{e}}-\frac{\overline{\boldsymbol{D}}^{\mathrm{e}} \boldsymbol{m}^{*} \boldsymbol{n}^{\mathrm{T}} \overline{\boldsymbol{D}}^{\mathrm{e}}}{H+\boldsymbol{n}^{\mathrm{T}} \overline{\boldsymbol{D}}^{\mathrm{e}} \boldsymbol{m}^{*}}\right] \dot{\varepsilon}_{\mathrm{m}}
$$

where $\bar{D}^{\mathrm{e}}$ is the elastic stiffness matrix in the normalised stress space and $m^{*}$ represents the unit normal vector of the plastic flow in the normalised stress space and is related to $m$ by:

$$
\boldsymbol{m}^{*}=\boldsymbol{m}+\overline{\boldsymbol{D}}^{\mathrm{e}-1}\left[\begin{array}{cc}
0 & k q v /(1-k \xi)^{2} \\
0 & 0
\end{array}\right] \boldsymbol{m}
$$

A full description of the model is given in Gajo and Muir Wood (1999).

\section{CALIBRATION AND SIMULATION}

\section{Calibration}

The present modelling approach requires the separate calibration of the parameters governing the behaviour of each constituent. The input parameters for the sand matrix are calibrated to obtain a good fit with the experimental results of unreinforced specimens, while the parameters for the fibres are calibrated considering both the fibre properties (like elastic Young's modulus) and the estimated contribution of fibres to the response of the composite.

\section{Input Parameters for Sand Matrix}

The Severn-Trent sand model requires two elastic and

\begin{tabular}{|c|c|c|}
\hline Parameter & Description & Value \\
\hline$\kappa$ & Slope of the elastic loading-unloading line on the $v_{\mathrm{m}}-\ln p^{\prime}$ plane & 0.01 \\
\hline$v$ & Poisson's ratio & 0.1 \\
\hline$\varphi^{\prime}$ & Critical-state friction angle & $35^{\circ}$ \\
\hline$\Gamma$ & Intercept for critical-state line on $v_{\mathrm{m}}-\ln p^{\prime}$ plane at $p^{\prime}=1 \mathrm{kPa}$ & 2.08 \\
\hline$k_{\mathrm{r}}$ & Link between changes in state parameter and current strength & 1.5 \\
\hline$B$ & Parameter controlling hyperbolic stiffness relationship & 0.0025 \\
\hline$R$ & Ratio of size of yield and strength surfaces & 0.1 \\
\hline$A$ & Multiplier in flow rule & 0.75 \\
\hline$k_{\mathrm{d}}$ & State parameter contribution in flow rule & 1.5 \\
\hline
\end{tabular}
eight plastic parameters. The values selected in this study are summarised in Table 1: the calibration procedure is described by Diambra (2010) using data from drained and undrained tests on unreinforced specimens.

Input Parameters for Fibres

The description of the behaviour of the fibres requires

Table 1. Values of soil parameters for Hostun sand 
the calibration of three different quantities (see Eq. (13)):

- the elastic modulus of the fibres, $E_{\mathrm{f}}$;

- the orientation distribution of the fibres, $\rho(\theta)$;

- the sliding function, $f_{\mathrm{b}}$, which defines the imperfect bonding between the fibres and the sand matrix.

However, in order to completely define the composite relationship shown in Eq. (13), the specific volume of the fibres $v_{\mathrm{f}}$, which defines the voids 'attached' to the fibres, $V_{\text {vf }}$, and therefore the partition of the volume of voids between fibres and sand matrix must also be chosen. Thus, $v_{\mathrm{f}}$ is considered here as an additional model parameter.

Diambra (2010) determined the elastic modulus $E_{\mathrm{f}}=$ $900 \mathrm{MPa}$ from a series of tensile tests on single fibres.

Diambra et al. (2007) determined that, in samples similar to those tested in this investigation, the distribution of fibre orientation $\rho(\theta)$ can be effectively described by:

$$
\rho(\theta)=\bar{\rho}\left(A+B\left|\cos ^{\mathrm{n}} \theta\right|\right)
$$

where the parameters $A, B$ and $n$ defining the orientation distribution were calibrated to be $A=0, n=5$ and $B=$ 2.04. However, for the difficulties encountered in the integration of the fibre stiffness matrix (Eq. (13)) when Eq. (30) was implemented, a slightly modified orientation distribution function $\rho(\theta)$ was introduced (as shown by Diambra et al., 2010):

$$
\rho(\theta)=\bar{\rho} \frac{2 a b^{2}|\cos (\theta)|}{\cos (\theta)^{2}\left(b^{2}-a^{2}\right)+a^{2}}
$$

where $a=1.095$ and $b=0.449$ are determined by forcing equality in Eqs. (30) and (31) at $\theta=0$ and by satisfying Eq. (14). These two constants define respectively the horizontal and vertical semi-axes of the ellipses when Eq. (31) is represented on a vertical plane as shown in Fig. 5. The assumed orientation is axisymmetric with respect to the vertical axis and describes an anisotropic distribution of fibres with preferred horizontal bedding.

The sliding function, $f_{\mathrm{b}}$, which indirectly accounts for the imperfect interfacial bond between fibres and sand grains, has the following form (Diambra, 2010):

$$
f_{\mathrm{b}}=K_{\mathrm{e}}\left(1-\exp \left(-c_{\mathrm{s}} \cdot \frac{p^{\prime}}{p_{\text {ref }}}\right)\right)
$$

where $K_{\mathrm{e}}$ is a coefficient of efficiency of the fibre-sand bonding and the bracketed component (which includes the mean stress of the sand matrix $p^{\prime}$ normalised with a reference pressure, $p_{\text {ref }}$, of $0.1 \mathrm{MPa}$ and a material constant $c_{\mathrm{s}}$ ) accounts for a confining pressure effect. Diambra (2010) calibrated the sliding function based on a back analysis of drained triaxial tests. In those tests, the imposed total stress path of the composite material is constrained to obey $\dot{q} / \dot{p}=3$ (Fig. 6). However, because of the confining stress contribution of the fibres, the effective stress path of the sand matrix is expected to follow a rather non-conventional stress path (Fig. 6) which must, however, end along the critical state line. The stress contribution from the fibres can be computed from the strains of the specimen (Eq. (17)) and this stress can subsequently be subtracted from the stresses in the composite (Eq. (11)) to obtain the stresses in the sand matrix. The

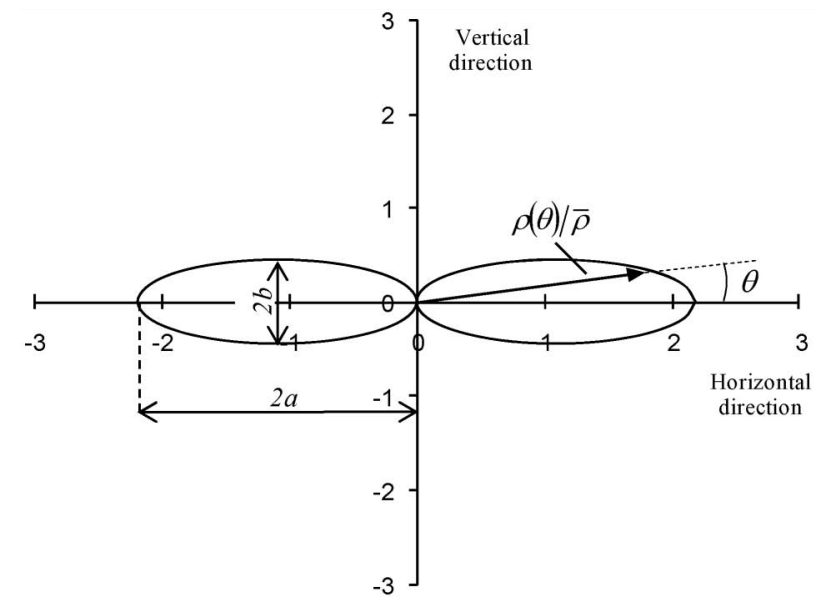

Fig. 5. Representation on a vertical plane of the fibre orientation distribution function according to Eq. (31) with $a=1.095$ and $b=$ 0.449

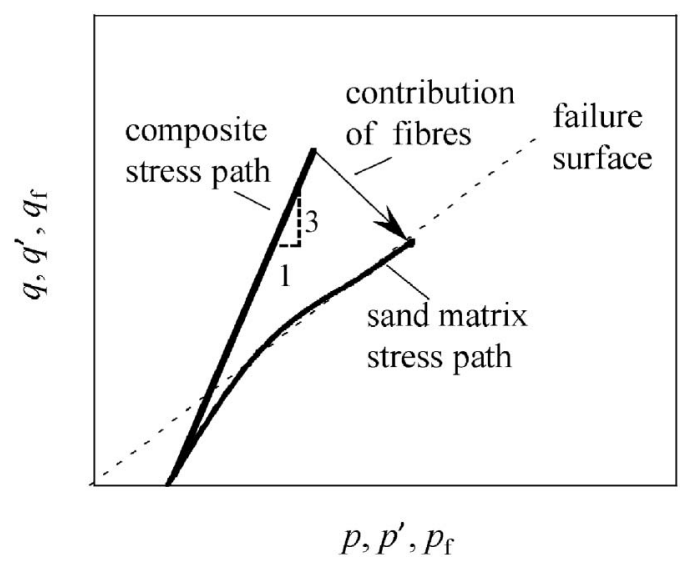

Fig. 6. Procedure for determination of the sliding function $f_{\mathrm{b}}$

resulting stresses in the sand matrix are then adjusted using the $f_{\mathrm{b}}$ function so that they ultimately approach the critical state failure surface for the unreinforced sand (Fig. 6). Values of $K_{\mathrm{e}}=0.5$ and $c_{\mathrm{s}}=0.75$ have been determined.

The concept of voids 'attached' to the fibres appears to be necessary to explain the apparent densification of the sand matrix induced by the inclusion of fibres (Ibraim et al., 2010; Diambra et al., 2010). While the volume of the voids 'attached' to the fibres might be expected to change during the loading process, the experimental evidence to reliably support such a variation has not yet been obtained and in the present modelling a constant specific volume of the fibres $\left(v_{\mathrm{f}}\right)$ is assumed. This constant has been calibrated by curve fitting the undrained response of a reinforced sample in both compression and extension as shown in Fig. 7, where the model simulations are represented by the thick continuous lines and the experimental data by a thin dashed line. A value of $v_{\mathrm{f}}$ equal to 3.27 has been determined.

A summary of the input parameters for the fibres is presented in Table 2 . 

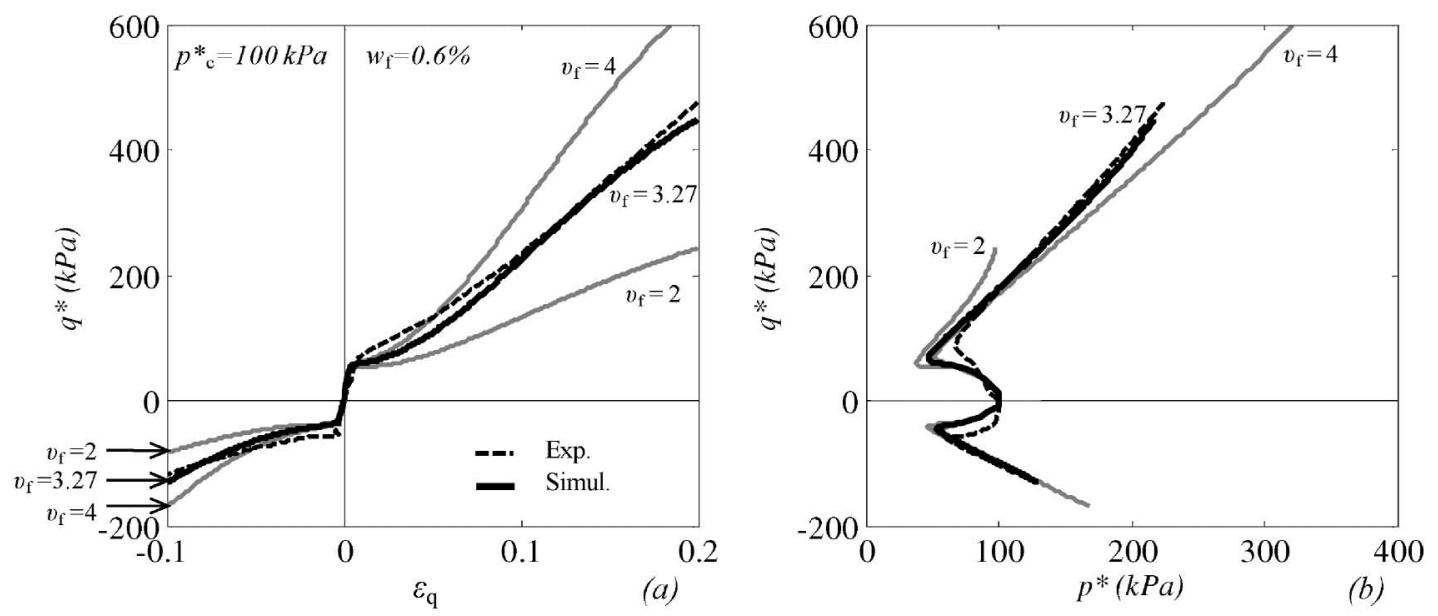

Fig. 7. Calibration of the specific volume of the fibres $v_{\mathrm{f}}$

Table 2. Parameters adopted for the fibres

\begin{tabular}{c|c|c}
\hline Parameter & Description & Value \\
\hline$E_{\mathrm{f}}$ & Elastic modulus & $900 \mathrm{MPa}$ \\
\hline$\rho(\theta)$ & $\begin{array}{c}\text { Fibre orientation } \\
\text { distribution }\end{array}$ & $\begin{array}{c}\rho(\theta)=\bar{\rho} \frac{2 a b^{2}|\cos (\theta)|}{\cos (\theta)^{2}\left(b^{2}-a^{2}\right)+a^{2}} \\
a=1.095 \quad b=0.449\end{array}$ \\
\hline$f_{\mathrm{b}}$ & Sliding function & $f_{\mathrm{b}}=K_{\mathrm{e}}\left(1-\exp \left(\begin{array}{c}-c_{\mathrm{s}} \cdot \frac{p^{\prime}}{p_{\mathrm{ref}}} \\
c_{\mathrm{s}}=0.75\end{array}\right)\right.$ \\
\hline$v_{\mathrm{f}}$ & $\begin{array}{c}\text { Specific volume } \\
\text { of the fibres }\end{array}$ & \multicolumn{2}{c}{3.27} \\
\hline
\end{tabular}

\section{Simulation of Undrained Tests}

This constitutive model has been used to simulate a series of undrained conventional triaxial tests on unreinforced and reinforced specimens. All the specimens were fabricated in a very loose state (relative density, $D_{\mathrm{r}} \approx 0 \%$ ) with fibre contents $w_{\mathrm{f}}=0.3 \%, 0.6 \%$ and $0.9 \%$. Prior to testing, all the samples were isotropically consolidated to 30,100 or $200 \mathrm{kPa}$ and then subjected to compression or extension triaxial loading under constant confining pressure. Full details of sample fabrication, and testing procedures are given by Ibraim et al. (2010).

Figures 8-10 compare model simulations with experimental test results for both compression and extension triaxial loading in $q^{*}-\varepsilon_{\mathrm{q}}, q^{*}-p^{*}$ and $\Delta u-\varepsilon_{\mathrm{q}}$ (where $\Delta u$ is the excess pore pressure) planes for different isotropic consolidation pressures. The model simulations are represented by the thick continuous lines whereas the experimental data are represented with thin dashed lines.

The initial stage of the model simulations is not noticeably affected by the presence of fibres. The level of strain is small, so that the fibres are not able to elongate and mobilise significant tensile forces. This observation that the initial behaviour of the composite is to a certain extent solely controlled by the sand matrix is also suggested by other studies (Heineck et al., 2005; Yetimoglu et al., 2005; Ibraim and Maeda, 2007).
At larger strains, the undrained behaviour of the reinforced specimens clearly diverges from that of the unreinforced specimens and the differences become appreciable especially after the characteristic state, the point of vertical tangency, $\delta p^{*} / \delta q^{*}=0$ (Ishihara et al., 1975). The model simulations predict very satisfactorily the observed change from the strain softening (liquefiable) behaviour of the unreinforced samples to the strain hardening behaviour of the reinforced samples for both compression and extension. In the $q^{*}-\varepsilon_{\mathrm{q}}$ plane (Figs. 8(a), 9(a), 10(a)), the model reproduces the observed increase in deviatoric strength associated with the fibre inclusions. However, it is clear that the deviatoric strength is much larger in compression than in extension for the same fibres content and this is also captured by the model.

The experimental undrained stress paths for reinforced specimens in compression and extension loading conditions (Figs. 8(b), 9(b), 10(b)) initially follow closely the stress paths of the unreinforced ones but at certain points the stress paths change direction sharply and show rapid increases in $p^{*}$ and then follow somewhat straight trajectories. The slopes of these trajectories are very different in compression and extension but the model simulates the asymmetry of this behaviour. Ibraim et al. (2010) showed that for a given fibre content and different confining pressures, the linear parts of the effective stress paths developed after the characteristic state run practically parallel to each other in compression as well as in extension. None of these lines intersects the origin of the $\left(q^{*}-p^{*}\right)$ plane, but the intercept on the positive $p^{*}$ axis (or lower intercept on the negative $q^{*}$ axis) increases with higher consolidation pressure. The simulations generally predict rather well the linear trend and the parallelism of the effective stress paths, as shown in Fig. 11.

The excess pore pressures of the reinforced specimens in compression as well as in extension typically show an initial increase up to a peak level significantly affected by the presence of fibres followed by a decrease which, for some amounts of fibres, can lead to a negative excess pore pressure. For a given consolidation pressure, the rate at which the excess pore pressure decreases with continued 

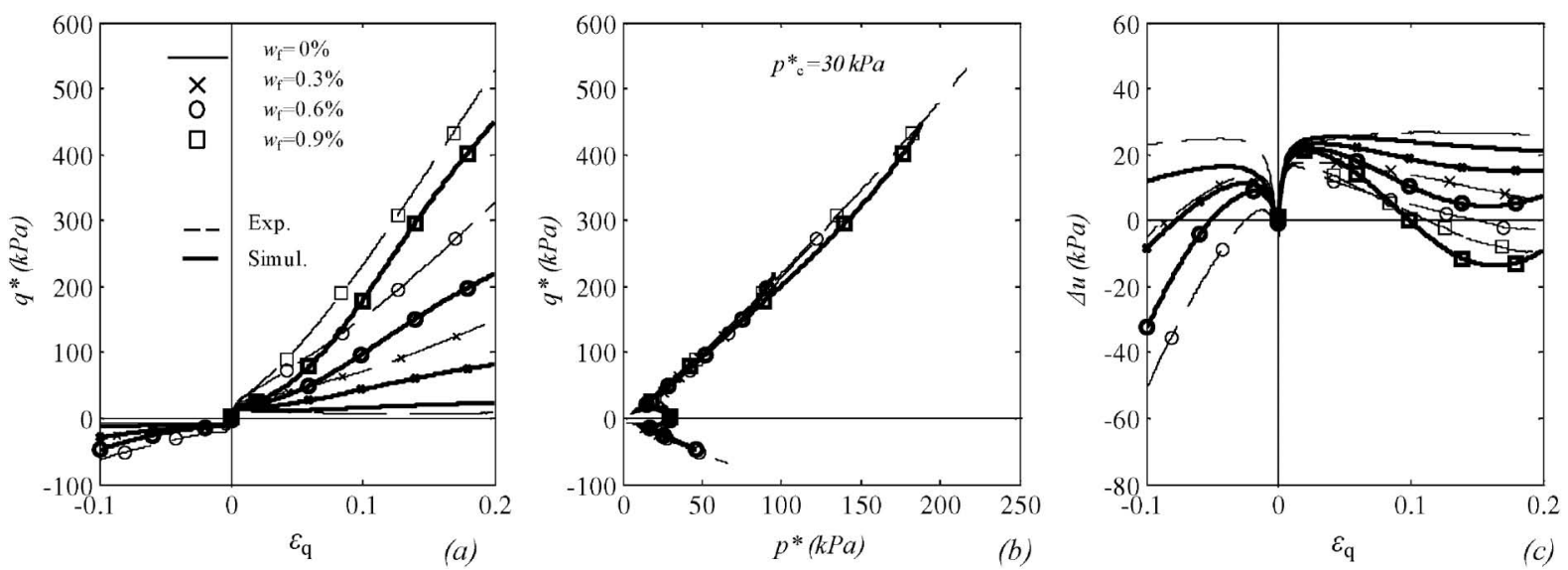

Fig. 8. Experimental results and model simulation for undrained tests at $30 \mathrm{kPa}$ cell confining pressure
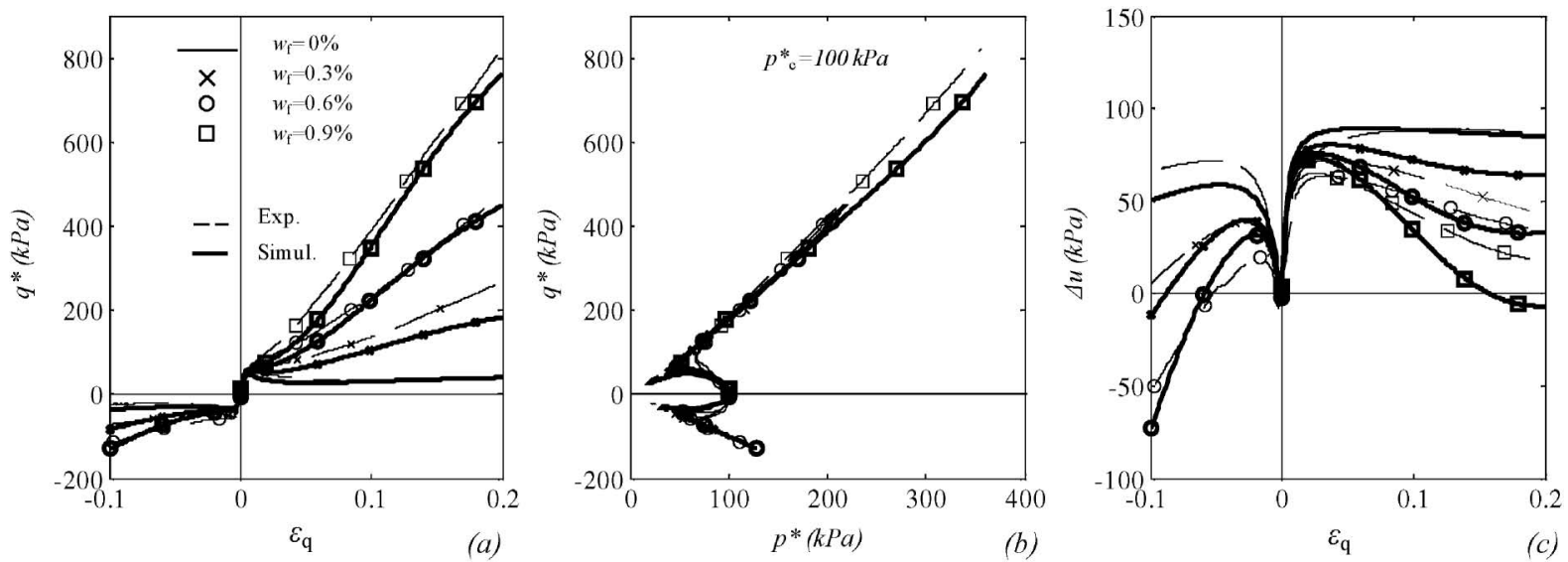

Fig. 9. Experimental results and model simulation for undrained tests at $100 \mathrm{kPa}$ cell confining pressure
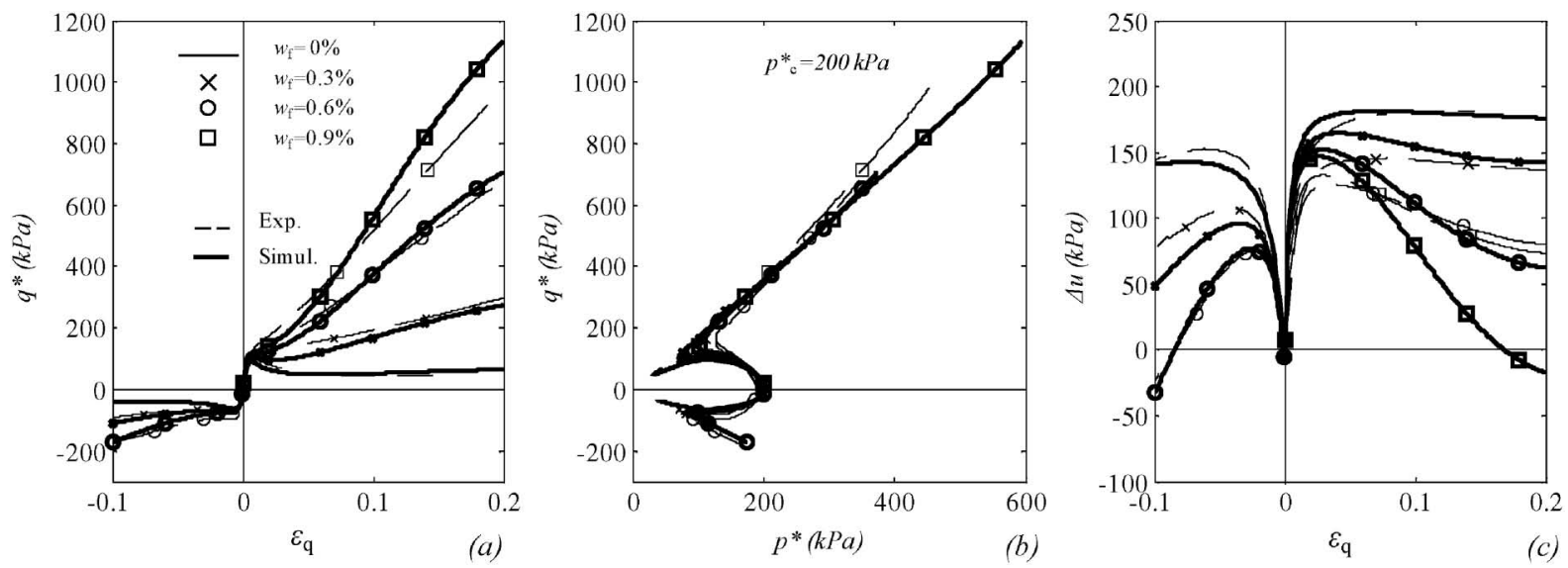

Fig. 10. Experimental results and model simulation for undrained tests at $200 \mathrm{kPa}$ cell confining pressure

straining is lower in compression than in extension and higher for higher fibre concentrations. These trends are also well captured by the model (Figs. 8(c), 9(c), 10(c)).

\section{DISCUSSION}

The modelling ingredients which permit the simulation of particular features of the undrained behaviour of fibre reinforced sands are discussed and analysed in this section.

\section{'Stolen' Void Ratio}

The conversion from a strain softening to a strain hardening material when fibres are added is mainly relat- 

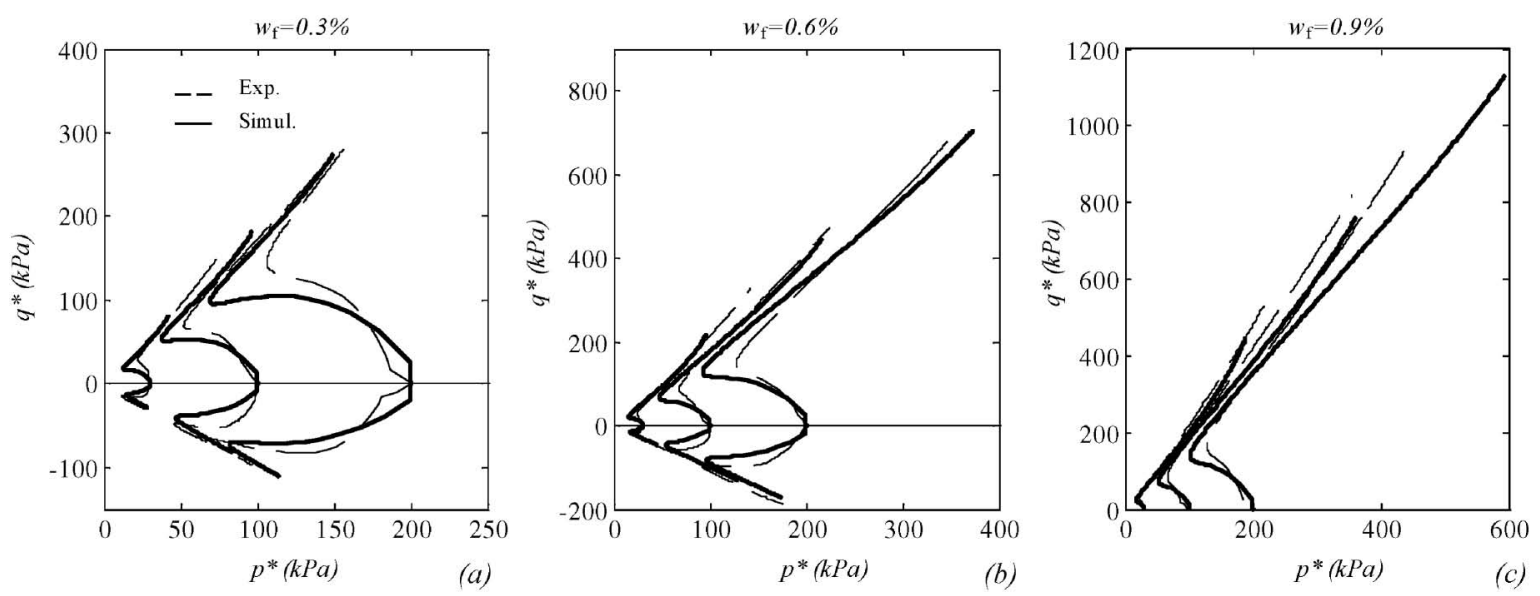

Fig. 11. Experimental results and model simulation for effective stress paths $\left(q^{*}-p^{*}\right)$ grouped according to fibre content
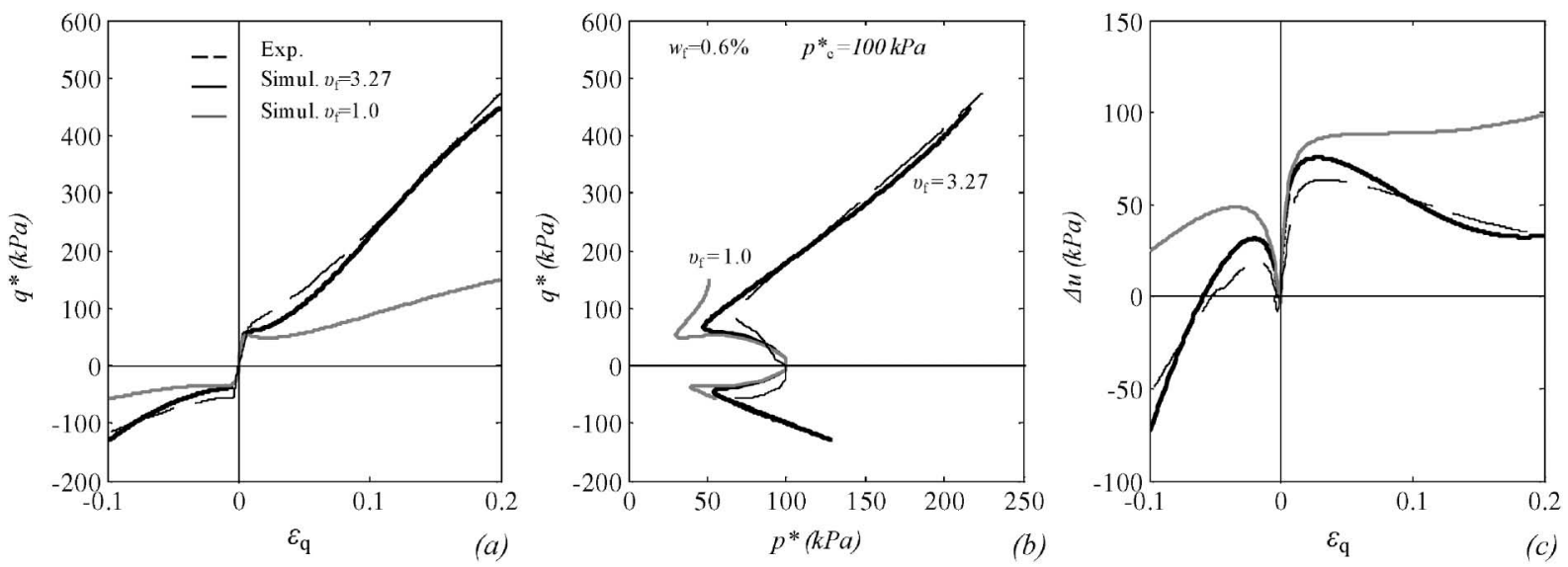

Fig. 12. Influence of accounting of voids repartition mechanism in the model simulations

ed to the partition of voids between the sand matrix and the fibres. The assignment of some voids to the fibres results in an apparent densification of the sand matrix which translates into an increased desire to dilate. Figure 12 shows a comparison between the experimental data and model simulations when no partition of volume of voids between sand and fibres is applied $\left(v_{\mathrm{f}}=1.0\right)$ and when the partition employed in the model is introduced $\left(v_{\mathrm{f}}=3.27\right)$. The consequence of not including the densification effect is clearly shown and leads to the overestimation of the excess pore pressure build up (Fig. 12(c)) which then leads to inaccurate simulations in the $q^{*}-\varepsilon_{\mathrm{q}}$ and $q^{*}-p^{*}$ planes (Figs. 12(a) and (b)). However, a refinement of the partition of the volume of voids needs to be further investigated as some evolution of $v_{\mathrm{f}}$ might be expected to occur with change of stress and/or strain levels. Exploration of the detail of this process, however, would require a very fine and reliable experimental estimation of the initial sample void ratio. The present procedures inevitably introduce some uncertainty at the stage of sample fabrication and saturation.

It is worth mentioning that in extension, where the stresses developed in the fibres are negligible, the slope of the linear effective stress path in the $q^{*}-p^{*}$ plane is not affected by the value of the specific volume of the fibres $v_{\mathrm{f}}$ (Fig. 12(b)). However, the neglect of the 'stolen' voids still leads to incorrect simulation of the excess pore pressures (Fig. 12(c)) and in turn of the deviatoric strength (Fig. 12(a)). The implied densification generated by the mere presence of the fibres together with the "stolen" voids remains important.

\section{Fibre Orientation}

The effect of the fibre orientation distribution on the model predictions has been investigated by considering a preferred horizontal, isotropic and preferred vertical initial orientation of fibres. The distribution of fibre orientation described in Eq. (31) and Table 2 has been selected as the preferred horizontal fibre orientation. Following Michałowski and Čermák (2002), the function $\rho(\theta)$, describing the distribution of fibre orientations, can be represented in a vertical plane as shown in Fig. 13. The preferred vertical orientation of fibres is represented by a vertical ellipse having a major axis with the same length as the preferred horizontal orientation. The analytical form of the orientation distribution function for the assumed vertical orientation of fibres is then: 


$$
\rho(\theta)=\bar{\rho} \frac{2 c d^{2}|\sin (\theta)|}{\sin (\theta)^{2}\left(d^{2}-c^{2}\right)+c^{2}}
$$

where $c=1.095$ and $d=1.00052$ are respectively the vertical and horizontal semi-axes of the ellipses with preferred vertical orientation shown in Fig. 13. The constants $c$ and $d$ have been determined by forcing equality of the major semi-axes of the ellipses in Eqs. (31) and (33) and by satisfying Eq. (14). The isotropic distribution of fibres orientation is represented with a circle in Fig. 13. It should be remarked that the sizes of the ellipses and circle in Fig. 13 are not related to the amount of the reinforcement: the same fibre content has been assumed for all the assumed orientation distributions, applying Eq. (14).

Model simulations with the different distributions of fibre orientation are shown in Fig. 14. For a given loading condition, the orientation of fibres does not strongly affect the deviatoric response of the soil in the $q^{*}-\varepsilon_{\mathrm{q}}$ plane (Fig. 14(a)). However, a clear dependence is noticeable in the $q^{*}-p^{*}$ plane where the slopes of the stress paths are consistently influenced by the imposed fibre orientation (Fig. 14(b)). For undrained compression, the slope of the stress path increases as the fibres are more horizontally oriented, while in extension the slope increases when the fibres become more vertical. It is clear that the more the

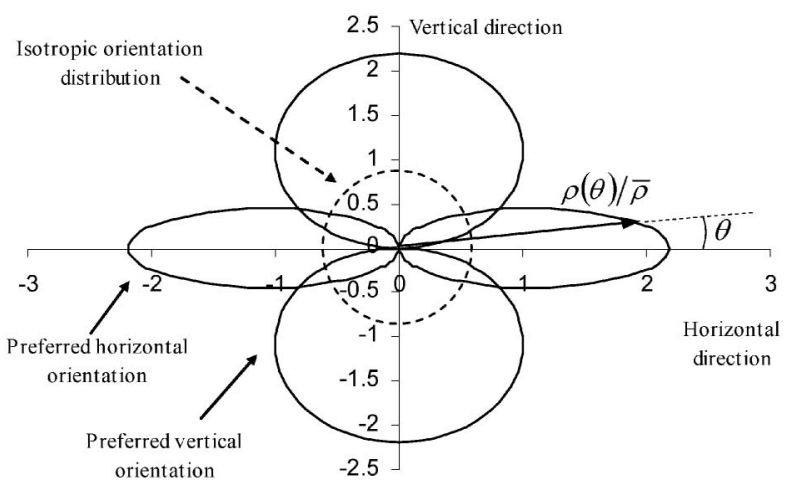

Fig. 13. Representation of the horizontal, vertical and isotropic orientation for fibres selected for investigating the influence of fibres orientation on the undrained behaviour fibres are oriented along directions subjected to tensile strains the steeper is the resulting slope of the effective stress path in the $q^{*}-p^{*}$ plane. It should be noticed that for undrained compression, there is only a small difference in the slope of the effective stress path when the isotropic and preferred vertical fibre orientation are assumed. This relates to the assumptions of the vertical axisymmetry of the assumed orientation distribution which results in a consistent proportion of sub-horizontal fibres even if a preferred vertical orientation is imposed as shown in Fig. 13.

In the $\Delta u-\varepsilon_{\mathrm{q}}$ plane (Fig. 14(c)), the magnitude of the pore pressure built up is also related to the fibre orientation. It is clear that the more the fibres are oriented to respond to the tensile strain, the bigger is their confinement effect and in turn the more pronounced is the resulting pore pressure built up.

\section{Strain Dependent Mobilisation of Fibre Contribution}

A schematic explanation of the behaviour of the sand matrix and contribution of the fibres to the stress state of the composite is given in Fig. 15, where the stresses for the composite, sand matrix and fibres are presented as computed by the model. Isotropic (Fig. 15(a)) and anisotropic horizontally preferred (Fig. 15(b)) orientation distributions of fibres are assumed. Simulations for the tests on reinforced samples with $0.6 \%$ fibre content and consolidation pressures of $100 \mathrm{kPa}$ and $200 \mathrm{kPa}$ are presented. According to the model, after the characteristic state is reached, the stress path of the sand matrix follows very closely the critical state line (Figs. 15(a) and (b)). The divergence of the composite stress path from the critical state line for the sand is clearly related to the contribution of the fibres. For a given axial strain level, it is clear that the stresses in the sand are largely confining pressure dependent, while the stress contribution of the fibres phase is rather independent of the confining pressure but dependent on the level of the strain. In Fig. 15, for two different confining pressures, the stress contributions of the fibres at axial strains are plotted by vectors and their lengths appear to be qualitatively similar for a given strain level. Again, the contribution of fibres is
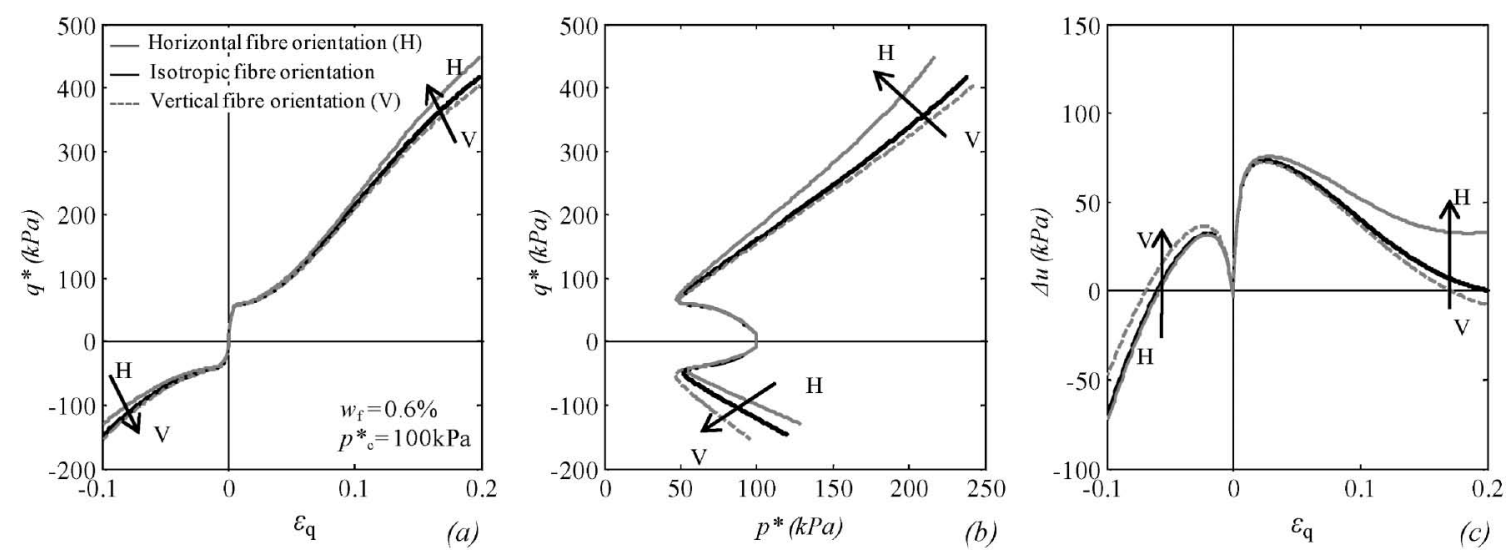

Fig. 14. Comparison between model predictions adopting different fibre orientation distributions 

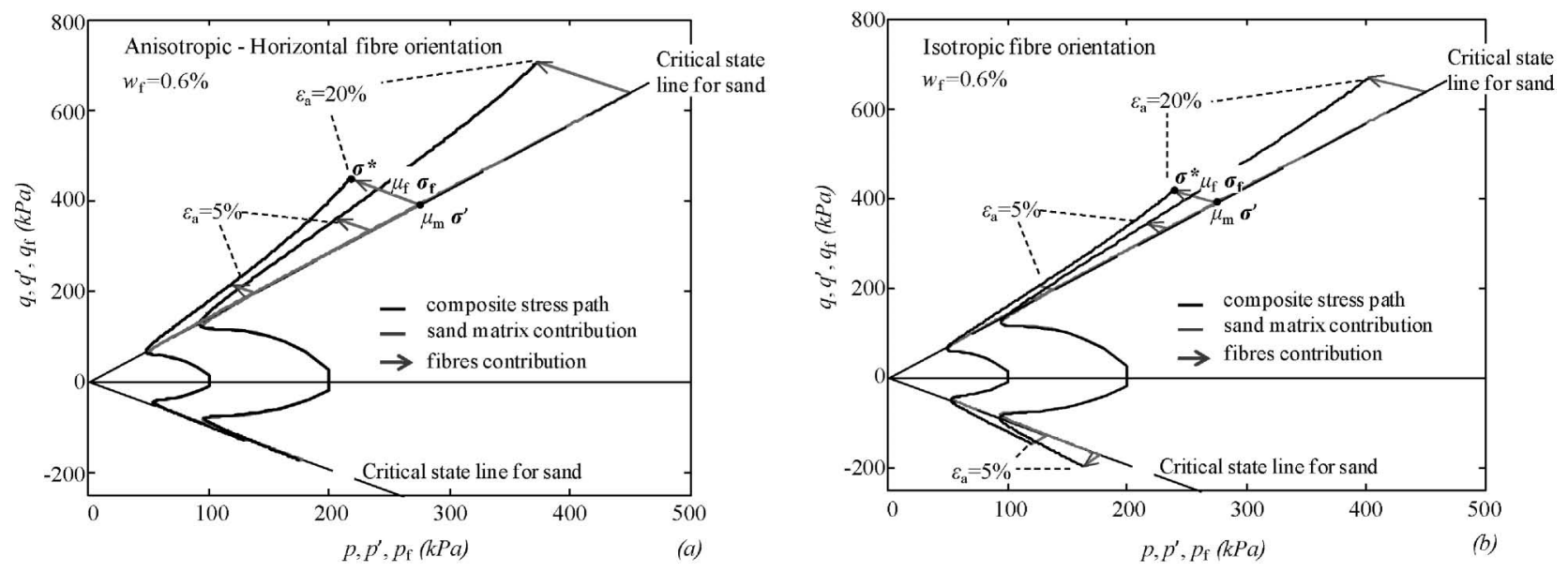

Fig. 15. Sand matrix and fibres contribution to the composite stress state for specimen reinforced with $w_{\mathrm{f}}=0.6 \%$ and preconsolidated to 100 and $200 \mathrm{kPa}$. (a) Anisotropic-horizontal fibre orientation and (b) isotropic fibre orientation

clearly dependent on fibre orientation. It can then be deduced geometrically that, after the characteristic state is reached, a unique stress path for the composite cannot develop for fibre reinforced sand. Furthermore, the effective stress paths for the composite appear to develop in a parallel manner as clearly shown by the experimental evidence (Ibraim et al., 2010).

\section{CONCLUSIONS}

The potential benefit of mixing fibres with loose clean sand to reduce the tendency to liquefaction has been reported by Ibraim et al. (2010) and it was found that the inclusion of fibres greatly affects the undrained behaviour of sands. A new constitutive model has been proposed and used to simulate the experimentally observed undrained behaviour of this fibre reinforced material.

The basic assumptions of the constitutive model were fixed by Diambra et al. (2010) but the subsequent refinements proposed by Diambra (2010) have been also included here. The modelling framework is based on the rule of mixtures which provides a high degree of freedom in selecting the appropriate constitutive relationships for its constituents. In this research, the Severn-Trent sand model (Gajo and Muir Wood, 1999) has been coupled with the matrix stiffness for fibres proposed by Diambra (2010). The resulting model is believed to have a rather high degree of sophistication and it accounts for the typical non-linear response of sands as well as any form of the fibre orientation distribution.

The following conclusions can be drawn:

- The model simulates very well the particular undrained behaviour of fibre reinforced sand observed experimentally in triaxial compression and extension;

- While the strain level appears to be important for the fibre/sand interaction process, the model successfully includes the key effects of the fibre orientation and reveals the importance of the apparent densification of the sand matrix induced by the presence of fibres.
The latter is taken into account by a model parameter which defines the partition of volume of voids between the sand matrix and fibres. However, further work may be necessary to investigate the extent to which this partition of the voids should be stress or strain dependent.

\section{REFERENCES}

1) Been, K. and Jefferies, M. G. (1985): A state parameter for sands, Géotechnique, 35(2), 99-112.

2) Brighenti, R. (2004): A mechanical model for fiber reinforced composite materials with elasto-plastic matrix and interface debonding, Computational Materials Science, 29, 475-493.

3) Consoli, N. C., Casagrande, M. D. T., Prietto, P. D. M. and Thome, A. (2003): Plate load test on fiber reinforced soil, Journal of Geotechnical and Geoenvironmental Engineering, 129(10), 951-955.

4) di Prisco, C. and Nova, R. (1993): A constitutive model for soil reinforced by continuous threads, Geotexiles and Geomembranes, 12(2), 161-178.

5) Diambra, A., Russell, A. R., Ibraim, E. and Muir Wood, D. (2007): Determination of fibre orientation distribution in reinforced sand, Géotechnique, 57(7), 623-628.

6) Diambra, A., Ibraim, E., Muir Wood, D. and Russell, A. R. (2010): Fibre reinforced sands: Experiments and modelling, Geotextiles and Geomembranes, 28, 238-250.

7) Diambra, A. (2010): Fibre reinforced sands: Experiments and modelling, PhD Thesis, University of Bristol, UK.

8) Ding, D. and Hargrove, S. K. (2006): Nonlinear stress-strain relationship of soil reinforced with flexible geofibers, Journal of Geotechnical \& Geoenvironmental. Engineering, ASCE, 132(6), 791-794.

9) Gajo, A. and Muir Wood, D. (1999): Severn-Trent sand: a Kinematic-hardening consitutive model: the q-p formulation, Géotechnique, 49(5), 595-614.

10) Gray, D. H. and Ohashi, H. (1983): Mechanics of fiber reinforcement in sands, Journal of Geotechnical Engineering, ASCE, 109(3), 335-353.

11) Gray, D. H. and Al-Refeai, T. O. (1986): Behaviour of fabric-versus fiber-reinforced sand, Journal of Geotechnical Engineering, ASCE, 112(8), 804.820.

12) Heineck, C. S., Consoli, N. C. and Coop, M. R. (2005): Effect of microreinforcement of soils from very small to large shear strains, Journal of Geotechnical and Geoenvironmental. Engineering, ASCE, 131(8), 1024-1033. 
13) Ibraim, E. and Maeda, K. (2007): Numerical analysis of fibre-reinforced granular soils, Proceedings of 5th International Symposium on Earth Reinforcement, Taylor \& Francis, Balkema, 387-393.

14) Ibraim, E., Diambra, A., Muir Wood, D. and Russell, A. R., (2010): Static liquefaction of fibre reinforced sand under monotonic loading, Geotextiles and Geomembranes, 28, 374-385.

15) Ishihara, K., Tatsuoka, F. and Yasuda, Y. (1975): Undrained deformation and liquefaction of sand under cyclic stresses, Soils and Foundations, 15(1), 29-44.

16) Li, J. and Ding, D. W. (2002): Nonlinear elastic behaviour of fiberreinforced soil under cyclic loading, Soil Dynamics and Earthquake Engineering, 22, 997-983.

17) Machado, S. L., Carvalho, M. F. and Vilar, O. M. (2002): Constitutive model for municipal solid waste, Journal of Geotechnical and Geoenvironmental. Engineering, ASCE, 128(11), 940-951.

18) Michałowski, R. L. (1997): Limit stress for granular composites reinforced with continuous filaments, Journal Engineering Mechanics, 123(8), 852-859.

19) Michałowski, R. L. and Cermák, J. (2002): Strength anisotropy of fiber-reinforced sand, Computers and Geotechnics, 29, 279-299.

20) Michałowski, R. L. (2008): Limit analysis with anisotropic fibre-reinforced soil, Géotechnique, 58(6), 489-501.

21) Roscoe, K. H., Schofield, A. N. and Thurairajah, A. (1963): Yielding of clays in states wetter than critical, Géotechnique, 13(3), 211-240.

22) Villard, P., Jouve, P. and Riou, Y. (1990): Modélisation du compertment mécanique du Texsol, Bulletin de liaison des laboratoires des ponts et chaussees, 168, 15-28.

23) Waldron, L. J. (1977): The shear resistance of root-permeated homogeneous and stratified soil, Soil Science Society of America Journal, 41(3), 843-849.

24) Yetimoglu, T., Inanir, M. and Inanir, O. E. (2005): A study on bearing capacity of randomly distributed fiber-reinforced sand fills overlying soft clay, Geotexiles and Geomembranes, 23, 174-183.

25) Zhu, Y. T., Zong, G. Manthiram, A. and Eliezer, Z. (1994): Strength analysis of random short-fibre-reinforced metal matrix composite materials, Journal of Material Science, 29, 6281-6286.

26) Zornberg, J. G. (2002): Discrete framework for equilibrium analysis of fibre-reinforced soil, Géotechnique, 52(8), 593-604.

\section{APPENDIX: STRESS-STRAN RELATIONSHIP FOR THE FIBRES PHASE}

For triaxial conditions, the incremental relationship between the single fibre strain at any angle $\theta$ from the horizontal $\left(\dot{\varepsilon}_{\theta(\mathrm{sf})}\right)$ and its axial and radial strains is given by the relationship:

$$
\dot{\varepsilon}_{\theta(\mathrm{sf})}=\dot{\varepsilon}_{\mathrm{a}(\mathrm{sf})} \sin ^{2}(\theta)+\dot{\varepsilon}_{\mathrm{r}(\mathrm{sf})} \cos ^{2}(\theta)
$$

$$
\left[\begin{array}{c}
\dot{\sigma}_{\mathrm{af}} \\
\dot{\sigma}_{\mathrm{rf}}
\end{array}\right]=\left[\begin{array}{l}
\frac{E_{\mathrm{f}}}{\mu_{\mathrm{f}}} \int_{1_{1}}^{l_{2}} \rho(\theta) \cos (\theta) \sin ^{4}(\theta) \mathrm{d} \theta \\
\frac{E_{\mathrm{f}}}{\mu_{\mathrm{f}}} \frac{1}{2} \int_{1_{1}}^{1_{2}} \rho(\theta) \cos ^{3}(\theta) \sin ^{2}(\theta) \mathrm{d} \theta
\end{array}\right.
$$

where the integration limits are $l_{1}=0$ and $l_{2}=\theta_{0}$ (where $\theta_{0}$ was defined in Eq. (16) for compression loading and $l_{1}=$ $\theta_{0}$ and $l_{2}=\pi / 2$ for extension loading as discussed in
Supposing that the fibres are a linear elastic material with modulus $E_{\mathrm{f}}$, the stress on the single fibres can be computed as:

$$
\dot{\sigma}_{\theta(\mathrm{sf})}=E_{\mathrm{f}} \dot{\varepsilon}_{\theta(\mathrm{sf})}
$$

and it is possible to decompose this into equivalent stresses acting in the directions of the axial and radial stresses, $\dot{\sigma}_{\mathrm{a}(\mathrm{sf})}(\theta)$ and $\dot{\sigma}_{\mathrm{r}(\mathrm{sf})}(\theta)$ :

$$
\dot{\sigma}_{\mathrm{a}(\mathrm{sf})}(\theta)=\dot{\sigma}_{\theta(\mathrm{sf})} \sin ^{2}(\theta) \quad \dot{\sigma}_{\mathrm{r}(\mathrm{sf})}(\theta)=\dot{\sigma}_{\theta(\mathrm{sf})} \cos ^{2}(\theta) / 2
$$

Following the procedures proposed by Zhu et al. (1994), the overall stress contribution of the fibres phase within the composite in the directions of the axial and radial stresses $\left(\mu_{\mathrm{f}} \dot{\sigma}_{\text {af }}\right.$ and $\left.\mu_{\mathrm{f}} \dot{\sigma}_{\mathrm{rf}}\right)$ has been obtained by integration of the stresses of the single fibres over a representative composite volume $(V)$ :

$$
\begin{aligned}
& \mu_{\mathrm{f}} \dot{\sigma}_{\mathrm{af}}=\frac{1}{V} \int_{\mathrm{V}} \rho(\theta) \dot{\sigma}_{\mathrm{a}(\mathrm{sf})}(\theta) \mathrm{d} V \\
& \mu_{\mathrm{f}} \dot{\sigma}_{\mathrm{rf}}=\frac{1}{V} \int_{\mathrm{V}} \rho(\theta) \dot{\sigma}_{\mathrm{r}(\mathrm{sf})}(\theta) \mathrm{d} V
\end{aligned}
$$

where $\rho(\theta)$ is the fibre orientation distribution function and represents the concentration of fibres in an infinitesimal volume $\mathrm{d} V$ having an orientation of angle $\theta$ above the horizontal plane (Fig. 2).

It is finally assumed an imperfect interfacial bonding between fibres and sand grains and the deformation of the single fibres is defined from the strain of the composite material as:

$$
\dot{\boldsymbol{\varepsilon}}_{(\mathrm{sf})}=f_{\mathrm{b}} \dot{\boldsymbol{\varepsilon}}
$$

where $f_{\mathrm{b}}$ is a dimensionless sliding function, similar to that used by Machado et al. (2002) and Brighenti (2004). $f_{\mathrm{b}}$ can vary between 0 and 1 with $f_{\mathrm{b}}=1$ for perfect bonding and $f_{\mathrm{b}}=0$ for full sliding.

If the orientation distribution is symmetrical with respect to the horizontal plane, Eqs. (A4) may now be rearranged and expanded by substituting Eqs. (A3), (A2), (A1) and (A5) to give:

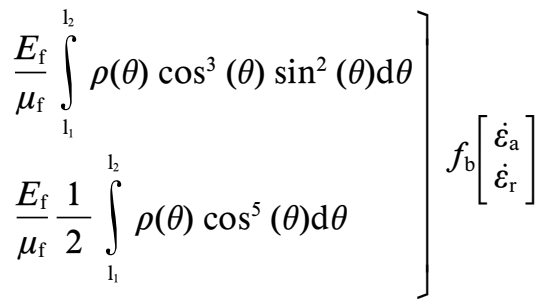

Constitutive Model for Fibres and shown in Fig. 3. More details are given in Diambra et al. (2010). 